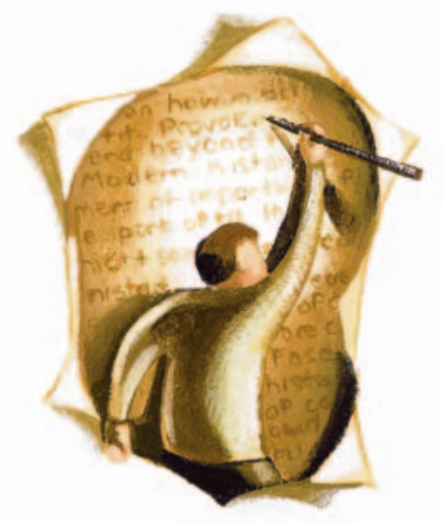

\section{Auricular acupuncture}

Neither the study by Taras Usichenko ${ }^{1}$ on auricular acupuncture for pain relief nor the accompanying commentary ${ }^{2}$ provide any information on the nature of the treatment that was being tested. One might be forgiven for assuming that auricular acupuncture is a form of traditional Chinese medicine, like body acupuncture. Few readers are probably aware that it was developed only in the I950s by a French physician, Paul Nogier. ${ }^{3}$ Although some experts believe that ear points were also used in traditional Chinese acupuncture, Nogier's auricular acupuncture is not based on traditional Chinese medical theory. Instead, an assumption that all internal organs are represented in the ear is the basis for auricular acupuncture. Therapists use maps that demonstrate these representations. One of the many problems with auricular acupuncture is that many such maps exist and little agreement exists regarding point location. Another problem is that all correspondence or reflex systems (e.g., auricular acupuncture, iridology and reflexology) fly in the face of our knowledge of anatomy and physiology.

\section{Edzard Ernst}

Professor of Complementary Medicine Peninsula Medical School

Exeter, UK

\section{REFERENCES}

I. Usichenko TI, Kuchling S, Witstruck T, et al. Auricular acupuncture for pain relief after ambulatory knee surgery: a randomized trial. CMAJ 2007;176 (2): $179-83$.
2. Buckley N. Auricular acupuncture for analgesia after arthroscopy [editorial]. CMAJ 2007;176(2):193-4 3. Nogier PMT. Handbook on auricular therapy. Moulins-les-Metz (France): Maisonneuve; I98I.

DOI:I0.1503/cmaj.1070008

\section{[Three of the authors respond:]}

We are grateful to Edzard Ernst for his comments concerning the origin and nature of auricular acupuncture, which we did not discuss in our recent article. ${ }^{1}$ The aim of our study was to test whether auricular acupuncture has analgesic properties, with groups of patients receiving acupuncture at specific acupuncture points or at nonacupuncture points (sham acupuncture). As we have now provided evidence for the effectiveness of auricular acupuncture ${ }^{1-3}$ we are planning to study the possible mechanisms underlying this therapy; it has been proposed that the endogenous opioid system plays a role. ${ }^{4}$

We mentioned the French origin of auricular acupuncture and our selection of Nogier's map of auricular points in our previous study, ${ }^{3}$ which we cited in our CMAJ article. One can certainly observe some parallels between auricular acupuncture, reflexology and iridology. However, when it comes to discussing potential mechanisms, we hesitate to compare auricular acupuncture, which has been shown to be effective in a number of animal studies and randomized clinical studies, ${ }^{1-4}$ with iridology, which is used only for diagnostic purposes and is considered to signal genotypes associated with certain medical conditions. ${ }^{5}$

\section{Taras I. Usichenko \\ Dragan Pavlovic \\ Michael Wendt}

Department of Anesthesiology and

Intensive Care Medicine

Ernst Moritz Arndt University

Greifswald, Germany

\section{REFERENCES}

I. Usichenko TI, Kuchling S, Witstruck T, et al. Auricular acupuncture for pain relief after ambulatory knee surgery: a randomized trial. CMAJ 2007;176 (2): $179-83$.
2. Usichenko TI, Dinse M, Hermsen M, et al. Auricular acupuncture for pain relief after total hip arthroplasty - a randomized controlled study. Pain 2005;II4:320-7.

3. Clement-Jones V, McLoughlin L, Tomlin S, et al. Increased beta-endorphin but not met-enkephalin levels in human cerebrospinal fluid after acupuncture for recurrent pain. Lancet I980;2(8201):946-9.

4. Asamoto S, Takeshige C. Activation of the satiety center by auricular acupuncture point stimulation. Brain Res Bull I992;29:157-64.

5. Um JY, An NH, Yang GB, et al. Novel approach of molecular genetic understanding of iridology: relationship between iris constitution and angiotensin converting enzyme gene polymorphism. Am JChin Med 2005;33:50I-5.

DOI:I0.I503/cmaj.I0700II

\section{Fundamental problem}

\section{with opioid trials for}

\section{chronic pain}

One problem with research on opioids for noncancer pain, in addition to those outlined by Andrea Furlan and associates, ${ }^{1}$ is the cognitive effect of these drugs, which makes it difficult to compare them with either placebo or active placebo such as NSAIDs. Even a nominal dose of opioids will improve mood through a euphoric effect. Tolerance develops such that the patient experiences intermittent withdrawal symptoms and smaller euphoric effects with trough and peak drug levels.

Under such conditions, patients will generally endorse the benefit of opioids for chronic noncancer pain. Euphoria is associated with pain relief and a greater sense of well-being, and the dysphoria and pain of withdrawal are associated with worsening chronic noncancer pain.

Further, it is often difficult for patients to recall how bad their pain was before they started treatment with opioids, and people taking opioids for chronic noncancer pain are likely to report an improvement in their overall condition even if they are worse off with the peak and trough effect of the opioid regimen. Perhaps they think that going without opioids altogether would feel like a trough: a state of withdrawal.

How else could research be done in 